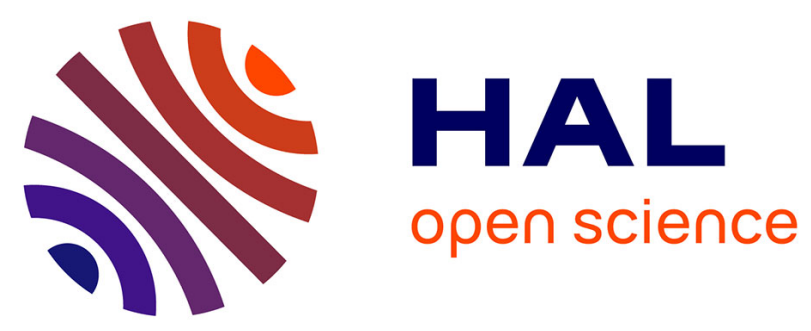

\title{
Thermomechanical Modelling of a Steel Plate Impacted by a Shot and Experimental Validation
}

Sébastien Rouquette, Emmanuelle Rouhaud, Hervé Pron, Manuel François, Christian Bissieux, Arjen Roos

\section{- To cite this version:}

Sébastien Rouquette, Emmanuelle Rouhaud, Hervé Pron, Manuel François, Christian Bissieux, et al.. Thermomechanical Modelling of a Steel Plate Impacted by a Shot and Experimental Validation. Materials Science Forum, 2006, 524-525, pp.167-172. 10.4028/www.scientific.net/MSF.524-525.167. hal-02283292

\section{HAL Id: hal-02283292 \\ https://hal-utt.archives-ouvertes.fr/hal-02283292}

Submitted on 3 May 2021

HAL is a multi-disciplinary open access archive for the deposit and dissemination of scientific research documents, whether they are published or not. The documents may come from teaching and research institutions in France or abroad, or from public or private research centers.
L'archive ouverte pluridisciplinaire HAL, est destinée au dépôt et à la diffusion de documents scientifiques de niveau recherche, publiés ou non, émanant des établissements d'enseignement et de recherche français ou étrangers, des laboratoires publics ou privés.

\section{(c)(1)}

Distributed under a Creative Commons Attribution| 4.0 International License 


\title{
Thermomechanical Modelling of a Steel Plate Impacted
}

by a Shot and Experimental Validation.

\author{
ROUQUETTE Sébastien ${ }^{1, a}$, ROUHAUD Emmanuelle ${ }^{1, b}$, PRON Hervé ${ }^{2, c}$, \\ FRANÇOIS Manuel ${ }^{1, \mathrm{~d}}$, BISSIEUX Christian ${ }^{2, \mathrm{e}}$, ROOS Arjen ${ }^{1, \mathrm{f}}$. \\ ${ }^{1}$ Institut Charles Delaunay, LASMIS, FRE CNRS 2848, Université de Technologie de Troyes, 12 \\ Rue Marie Curie, 10010 TROYES Cedex (France). \\ ${ }^{2}$ Unité de Thermique et Analyse Physique (UTAP EA3802), Laboratoire de ThermoPhysique \\ (LTP), Université de Reims Champagne - Ardennes, Moulin de la Housse B.P. 103951687 \\ REIMS Cédex (France). \\ a rouquette@utt.fr, ${ }^{b}$ rouhaud@utt.fr, ${ }^{\mathrm{c}}$ herve.pron@univ-reims.fr, \\ d francois@utt.fr, ${ }^{\mathrm{e}}$ christian.bissieux@univ-reims.fr, ${ }^{\mathrm{f}}$ arjen.roos@utt.fr
}

Keywords : shot peening, shot impact, thermomechanical modelling, finite elements, residual stresses, infrared thermal measurements.

\begin{abstract}
:
This work presents an experimental and numerical study of the thermo-mechanical problem of a steel plate impacted by a shot. The temperature rise is estimated and its effect on the compressive residual stress is analyzed. The simulations show that the value of the compressive residual stresses at the surface of the plate is modified when thermo-mechanical effects are included in the model as compared with simulation including hardening effects only. To validate this numerical study, an experimental device has been developed to measure the temperature rise after the impact. The experiment consists of the impact of a shot on a metallic plate. The temperature measurement is performed by an infrared camera located on the side of the plate opposite to the impact. Comparison between these experimental measurements and the numerical solution gives good agreement (to within 5\%).
\end{abstract}

\section{Introduction}

Shot peening is a mechanical process of surface treatment used to generate compressive residual stresses in mechanical parts. This enhances several mechanical properties of the workpieces, such as fatigue life ${ }^{[1]}$. The shot peening process consists of deforming the surface of a workpiece by bombarding it with shots of metal. The prediction of the compressive residual stresses is of great interest to control the process, but it is rather complicated due to the large number of experimental parameters such as the mechanical properties of the treated material, the velocity, radius and properties of the shot, the duration of the treatment, etc. Industrially, the so-called normalised Almen strip ${ }^{[2]}$ is used to predict the compressive residual stresses in the mechanical part treated. However, the Almen strip does not allow to predict correctly the residual stresses field, because the mechanical properties of the material treated are different from the Almen strip,... ${ }^{[3]}$. Moreover, experimental study of the generation of residual stresses is expensive to carry out. Simulating shot peening by finite element models is cheaper and allows carrying out a great number of simulations with different parameters.

Several studies deal with the impact of one or more shot on a work-piece, where the topics of interest are the influence of shot radius and impact velocity, mechanical properties of the workpiece, etc. ${ }^{[4,5]}$. A 3D finite element analysis of several impacts has shown that in some cases the numerical results fit with experimental residual stress measurements ${ }^{[6]}$. However, these models do not take in account the heat dissipation due to the plastic deformation. Experimental measurements 
of temperature have recorded a temperature rise of around $15^{\circ} \mathrm{C}-20^{\circ} \mathrm{C}$ on the rear side of a shotpeened Almen sample ${ }^{[7]}$. The temperature rise of temperature on the impact side is unknown and undoubtedly higher than at the measured rear side. Thus, in this paper, the focus is on the influence of the heating on the residual stresses. An experimental device has been developed at the University of Reims (UTAP) to measure the temperature rise of a plate impacted by a hardened shot. An infrared camera measures the non-impacted side of the plate. In addition to this experimental study, a simulation of a single impact on the plate is carried out by the finite element method. The first objective of this simulation is to verify that the calculated temperature is close to the measured one. The second objective is to evaluate the effect of the temperature rise on the residual stresses.

\section{Experimental device and thermal measurements}

The experimental device is shown in figure 1. The apparatus is composed of four parts: (i) the pneumatic system which shoots the shot, (ii) a camera which is used to record the impact velocity, (iii) an infrared camera which is employed to measure the heating of the plate and (iv) the plate itself.

The diameter of the shot is $4.5 \mathrm{~mm}$. The impact velocity, about $80 \mathrm{~m} / \mathrm{s}$, is recorded by a high speed camera. The shot is much harder than steel plate, which is made of 316L steel with a yield stress of $280 \mathrm{MPa}$. The dimensions of the plate are $140 \mathrm{~mm} \times 100 \mathrm{~mm} \times 3 \mathrm{~mm}$.

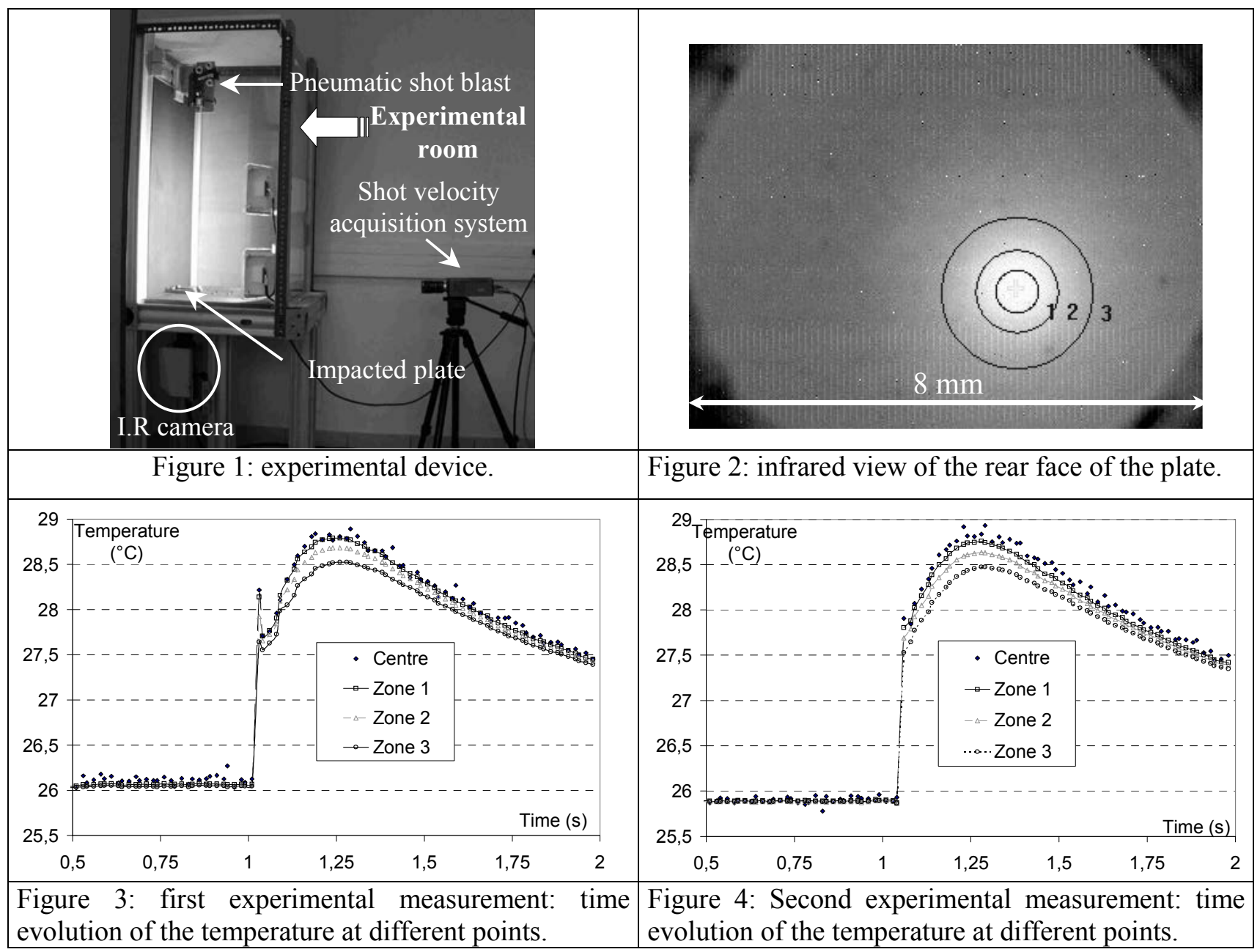

The thermal measurements are made by an infrared camera which is located under the experimental chamber. The plate is fixed on an iron support containing a hole (diameter $d=8 \mathrm{~mm}$ ) just below the impact site to allow the thermal measurement. The frequency used for the thermal acquisition presented in this work is $60 \mathrm{~Hz}$. The spatial resolution employed for this measurement is the size of one pixel (detector): about $30 \mu \mathrm{m}$. If we take in account the correlation of the detector, optical distortion, etc., the spatial resolution becomes $50 \mu \mathrm{m}$. The thermal resolution is limited by 
the proper noise of the acquisition device, which is $21 \mathrm{mK}$. However, this theoretical limit is never reached for any configuration of the acquisition device because the measured temperatures are around $2.5^{\circ} \mathrm{C}-3^{\circ} \mathrm{C}$.

The thermal measurements are presented in figures 2, 3 and 4. Figure 2 depicts the radiation scanned by the infrared camera at the rear face of the plate. The numbers 1,2 and 3 describe three regions (or zone) of the plate. These zones are used to average the temperature of the plate over several pixels. The temporal evolution of the temperature for each zone is reported in figures 3 and 4. For the three zones, the evolution of the temperatures is essentially the same. The temperature estimated for zone 1 is the highest but exhibits more noise than the two other zones. This is due to the lower number of pixels on which the temperature is averaged. The observed peak of temperature occurs $0.25 \mathrm{~s}$ after the beginning of the impact. The rise of temperature reaches a maximum of $2.7^{\circ} \mathrm{C}$ on the rear side of the plate. These measurements show a satisfying reproducibility of the results. In the next section, the temperature rise on the rear side of the plate will be modelled by a finite element method.

\section{Finite Elements Method \& Thermo-mechanical Modelling}

The shot is assumed to have an elastic behaviour, because its yield stress is generally as high upper as $1200 \mathrm{MPa}$, whereas the 316L steel yields at around $280 \mathrm{MPa}$. We have studied two impact velocities of $(70 \mathrm{~m} / \mathrm{s}$ and $80 \mathrm{~m} / \mathrm{s})$ with a shot of $4.5 \mathrm{~mm}$ diameter. The impact direction is normal to the face of the plate, so consequently an axisymmetric geometry is used for the simulation (figures 5 and 6). The mechanical and thermal boundary conditions are presented in figure 5 . The meshes of the shot and the plate are depicted in figure 6 . The mesh is strongly refined directly under the impact site where the plastic deformation is important. The ratio of the size of the smallest element to the shot radius is $6.67 \times 10^{-3}$.

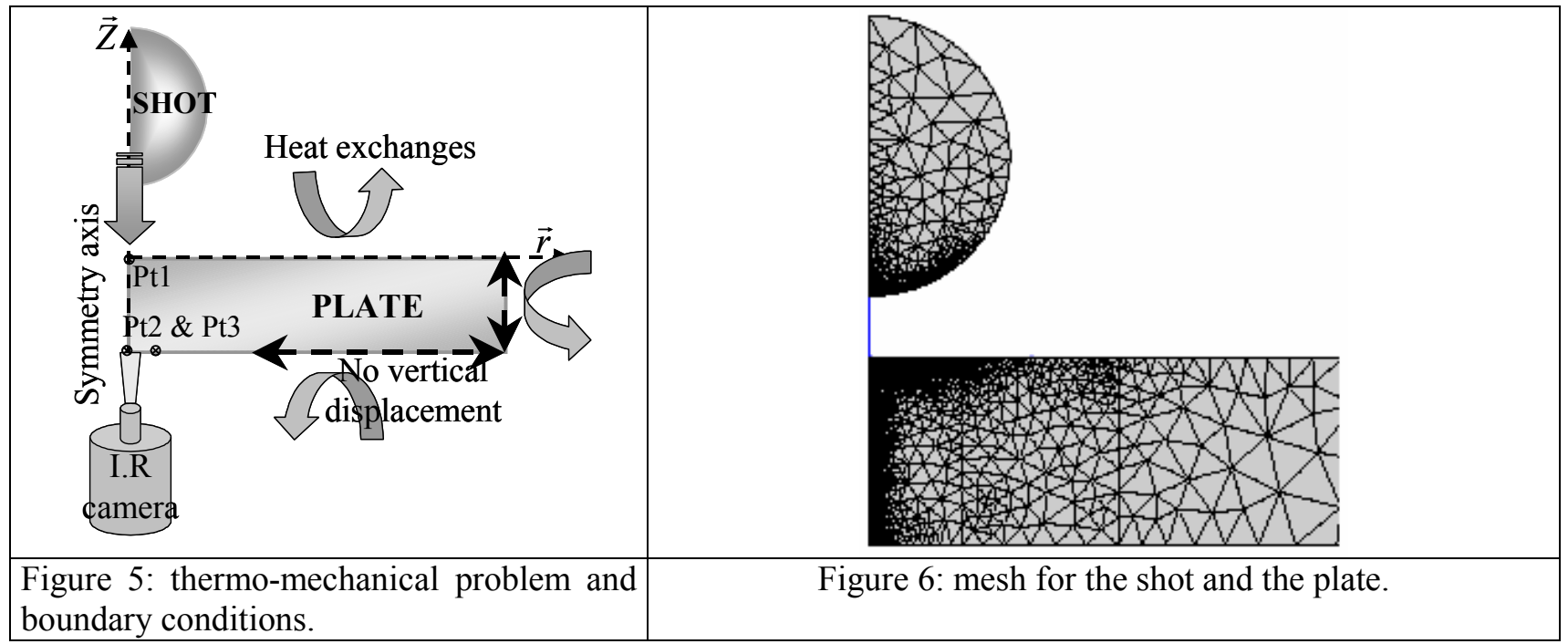

The physical properties of the $316 \mathrm{~L}$ steel plate is reported in the table 1 . In the mechanical problem, the temperature change is taken into account by the thermal dilatation. The plate has a thermo-elasto-plastic constitutive law with a non-linear isotropic hardening. The physical and mechanical parameters are supposed to be independent of temperature, because the temperature changes are moderate (lower than $100 \mathrm{~K}$ ). The non-linear isotropic hardening law is given by the following expression, as a function of the yield stress $\sigma_{\mathrm{Y}}$ and the cumulated plastic deformation $p$ : $\sigma=\sigma_{Y}+Q(1-\exp (-b . p))^{[8]}$. where $Q$ is the saturation hardening coefficient, $b$ is the saturation rate and $p$, the cumulated plastic deformation is defined by the following formula : $p=\int\left(\frac{2}{3} \dot{\varepsilon}_{p}: \dot{\varepsilon}_{p}\right)^{1 / 2} d t$. 
The thermal problem is coupled to the mechanical problem through the source term in the heat conduction equation : $\rho C_{P} \frac{\partial T}{\partial t}-\operatorname{div}(\lambda \cdot \overrightarrow{\operatorname{grad}} T)=\beta\left(\sigma: \dot{\varepsilon}^{p}\right)$ dans $\Omega \times I$

where $T(r, z ; t)$ is the temperature at point $(r, z) \in \Omega$ at time $t \in I=[0 ; 0.6 s], \Omega$ is the steel plate, $\sigma$ is the stress tensor and $\varepsilon$ is the strain tensor. $\beta$ is a dimensionless coefficient, expressing the fraction of plastic work that is converted (dissipated) into heat, which is found experimentally to lie between 0.8 and $1^{[9]}$. We have chosen it at 0.9 for our simulations.

Table 1: Physical and mechanical properties of 316L steel

\begin{tabular}{l|c}
\hline \multicolumn{1}{c|}{ Model parameter } & Value \\
\hline Young's modulus $(\mathrm{GPa})$ & 210 \\
Yield Stress $(\mathrm{MPa})$ & 280 \\
Poisson ratio & 0,28 \\
Thermal dilatation coefficient $\left(\mathrm{K}^{-1}\right)$ & $16,6 \mathrm{e}-6$ \\
Specific mass $\left(\mathrm{kg} / \mathrm{m}^{3}\right)$ & 7900 \\
Saturation hardening Q $(\mathrm{MPa})$ & 660 \\
Saturation rate b & 5 \\
Thermal conductivity coefficient $(\mathrm{W} / \mathrm{m} / \mathrm{K})$ & 16 \\
Specific heat $(\mathrm{J} / \mathrm{kg} / \mathrm{K})$ & 500 \\
Global exchange coefficient $\left(\mathrm{W} / \mathrm{m}^{2} / \mathrm{K}\right)$ & 20 \\
Room temperature $\left({ }^{\circ} \mathrm{C}\right)$ & 20 \\
\hline
\end{tabular}

The coupled thermo-mechanical problem is solved by the finite element code ZéBuLoN. The 12042 node mesh is presented in figure 6 . The calculation was carried out on a Unix station with a $2.4 \mathrm{GHz}$ Opteron CPU and $4 \mathrm{~Gb}$ of RAM. Five days (time "wall clock") were necessary to run the simulation. The cooling phase (after the rebound of the shot) is the phase that needs the longest time.

\section{Numerical results}

The calculated temperatures are presented in figures 7 to 11 and the calculated residual radial stress $\sigma_{\text {rr }}$ in figure 12.

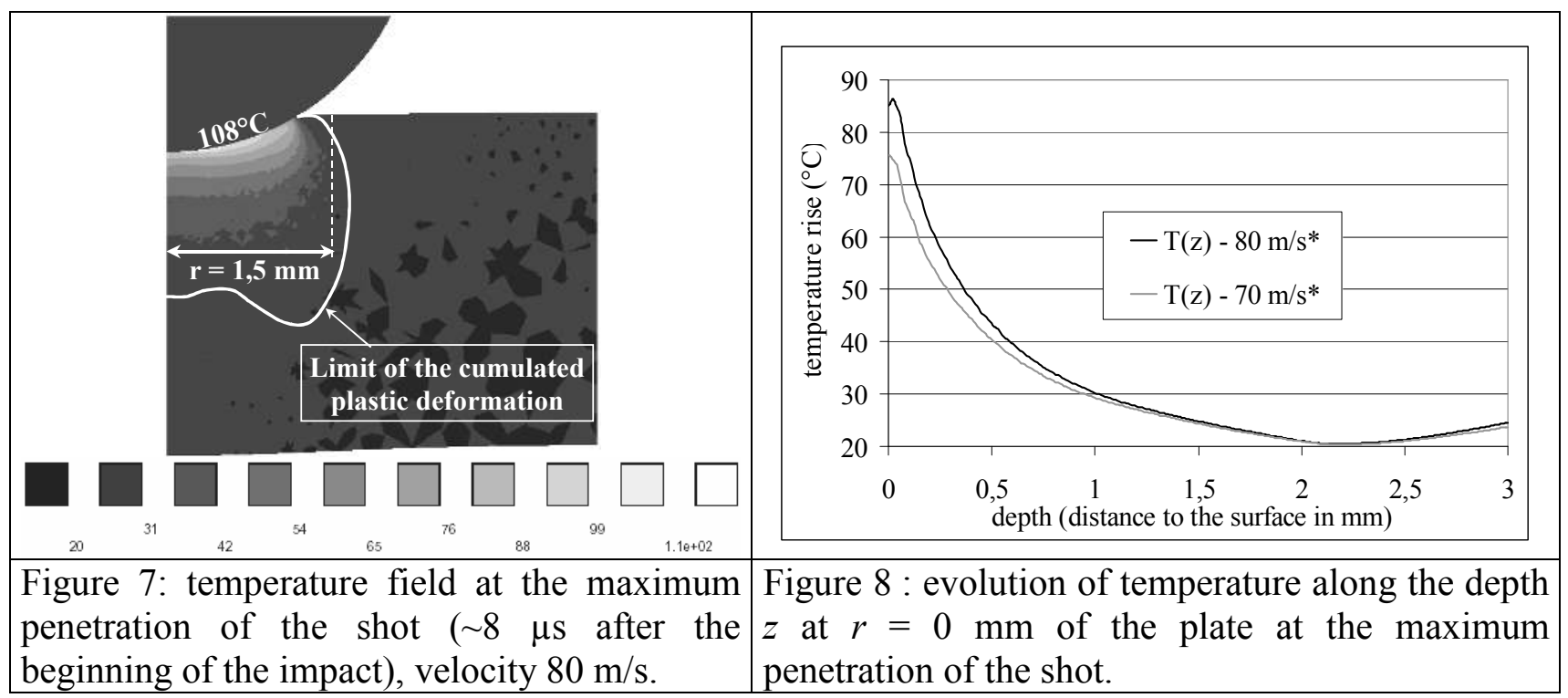

The temperature field at the maximum penetration of the shot is shown in figure 7 . It can be observed that the heat source is located directly under the surface of the indentation. The maximum temperature is located at the surface close to the axis of symmetry. Due to the short duration of the impact (about $11 \mu \mathrm{s}$ ), the heat has not yet diffused into the work-piece. Hence, the temperature distribution is similar to the distribution of the cumulated plastic strain at the same instant. 
Then, the second peak appears around time $t=0.25 \mathrm{~s}$, just as in the experimental measurement. This second peak is due to the heat diffusion from the front to the rear of the plate. The rise of temperature at this second peak is around $3.2^{\circ} \mathrm{C}$ for an impact velocity of $80 \mathrm{~m} / \mathrm{s}$ and $2.8^{\circ} \mathrm{C}$ for 70 $\mathrm{m} / \mathrm{s}$. These calculated temperatures are close to the ones measured experimentally, as discussed below.

Figure 11 shows a comparison of the calculated temperatures at the rear side $(z=3 \mathrm{~mm})$ for the case $70 \mathrm{~m} / \mathrm{s}$ with their experimental counterparts. They fit well (to within $5 \%$ ) except for the first temperature peak. The calculated temperature rise is twice the experimental value, but the second peak, due to the heat diffusion, is similar.

Figure 12 represents the residual radial stresses $\sigma_{\text {rr }}$ for the case including thermal effect (*) and the case without $(* *)$. It appears that the case including thermal effects provides a strong tensile residual radial stresses. For the case without thermal effect this residual stress reaches $300 \mathrm{MPa}$ at the top surface $(z=0 \mathrm{~mm})$, whereas including the thermal effect leads to values of 600 to $700 \mathrm{MPa}$. In fact, the cooling of the plate produces a thermal relaxation of the stresses. The coupling thermalMechanical is performed by the thermal dilatation coefficient in the mechanical problem. So, the decrease of temperature during the cooling step induces a contraction of the heat affected zone, by consequence, a change in the radial stress profile. The difference (between the case including thermal effect and the case without) decreases in the depth of the plate and it is only observable in the heat affected zone, figure 7.

\section{Conclusion}

This work presents an experimental apparatus which consists of the impact of a plate by a hardened shot. The experimentally measured temperatures have been shown. Then, a thermomechanical model has been established to reproduce the experiment and to study the influence of the heat dissipation on the residual radial stresses.

We have obtained a good agreement between the temperature calculated from the thermomechanical simulation with the one measured on the plate. The heating measured at the rear face of the place is around $2.8^{\circ} \mathrm{C}$ and the calculated heating is around $2.7^{\circ} \mathrm{C}-3^{\circ} \mathrm{C}$ for an impact velocity of $70 \mathrm{~m} / \mathrm{s}-80 \mathrm{~m} / \mathrm{s}$ respectively. An initial difference between the calculated and measured temperatures occurs during the impact. This difference is probably due to a bending of the plate. The effect of the heating on the residual stresses has been investigated. It seems that a thermal relaxation of the stresses occurs during the cooling of the plate. This effect is not negligible in the heat affected zone.

\section{References}

[1] K.J. Marsh. Shot Peening : Techniques and Applications. Engineering Materials Advisory Services Ltd., London, 1993.

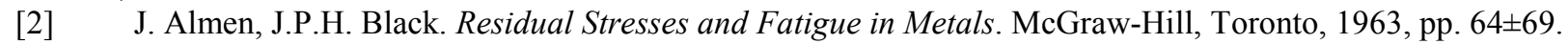

[3] R. Herzog, W. Zinn, B. Scholtes, H. Wohlfahrt. The significance of Almen intensity for the generation of shot peening residual stresses. Proceedings of the Sixth International Conference on Shot Peening, ICSP6, San Francisco, CA, 1996, pp. $270 \pm 281$.

[4] David Deslaef, Modélisation numérique du grenaillage de précontrainte: approche tridimensionnelle et dynamique. Université de Technologie de Troyes, Thèse de Doctorat (2000).

[5] G.H. Majzoobi ., R. Azizi, A. Alavi Nia. A three-dimensional simulation of shot peening process using multiple shot impacts. Journal of Materials Processing Technology 164-165 (2005) pp. 1226-1234.

[6] S.A. Meguid, G. Shagal, J.C. Stranart, Three-dimensional finite element analysis of peening of strain-rate sensitive materials using multiple impingement model, Int. J. Impact Eng. 27 (2002) 119-134.

[7] H. Pron, J.-F. Henr, B. Flan, J. Lu, S. Offermann et J.L. Beaudoin. Estimation of residual stresses induced by shot-peening. Measurement of the thermal dissipation with an infrared camera. Int. J. Therm. Sci. 41 (2002) pp. 369375 .

[8] J. Lemaître et J-L. Chaboche. Mécanique des matériaux solides. DUNOD, $2^{\text {ième }}$ édition.

[9] P. Rosakis, A.J. Rosakis, G. Ravichandran, J. Hodowany. A thermodynamic internal variable model for the partition of plastic work into heat and stored energy in metals. Journal of the Mechanics and Physics of solids. Vol. 48, pp. 581-607 (2000). 